\title{
Más allá de las estrategias étnicas: tácticas empresariales de inmigrantes como procesos creativos y dinámicos
}

\author{
Catarina Andreia dos Reis de Oliveira \\ Alto Comisariado para la Inmigración y el Diálogo Intercultural \\ catarina.oliveira@acidi.gov.pt
}

\section{Resumen:}

En este articulo se propone y presenta un modelo beurístico de estrategias empresariales que considera la diversidad de tácticas de los inmigrantes y los limites de la generalización de las explicaciones de sus estrategias. El modelo se comprueba y se explica a partir de datos recogidos en un trabajo comparativo de investigación empírica con empresarios chinos, indios y caboverdianos establecidos en Portugal. Se pretende mostrar de este modo la diversidad y complejidad de las estrategias empresariales de los inmigrantes.

Palabras clave: inmigrantes, estrategias étnicas, empresarios.

\begin{abstract}
This article proposes and presents a beuristic model of business strategies which considers the diverse tactics adopted by immigrants and the limits of the generalizations regarding immigrant strategies. The model is tested and explained using data collected for empirical comparative research into Chinese, Indian and Cape Verdean entrepreneurs living in Portugal. The article tries to show the diversity and complexity of the business strategies adopted by immigrants.
\end{abstract}

Key words: immigrants, ethnic strategies, entrepreneurs 


\section{Introducción}

El estudio de las estrategias empresariales de los inmigrantes se ha convertido en un tema importante en la literatura científica acerca de los flujos migratorios. Desde mediados de la década de 1970, el análisis de los empresarios inmigrantes se ha incorporado al corpus de las ciencias sociales. El reconocimiento de su importancia resultó del crecimiento e impacto de las iniciativas empresariales inmigrantes en diversos contextos de acogida (Kloosterman y Rath, 2003: 3).

Desde entonces han surgido numerosos argumentos para explicar qué grupos de inmigrantes son más propensos a desarrollar actividades empresariales. Las principales contribuciones aparecidas a lo largo de estas últimas décadas se tradujeron en la identificación de dos grandes ejes explicativos: 1) las características del grupo inmigrante y 2) las condiciones del contexto de acogida en su vertiente económica, social, política e institucional.

El primer eje explicativo, desarrollado esencialmente en Estados Unidos, se asoció a la identificación de características culturales y solidaridades inherentes a las comunidades empresariales inmigrantes. Algunos investigadores hallaron incluso evidencias de que algunas comunidades inmigrantes construyen mercados cerrados y protegidos (enclaves étnicos) que garantizan rendimientos más altos de los que conseguirían en una economía «abierta ${ }^{1}$ (Wilson y Portes, 1980; Portes y Manning, 1986; Portes y Stepick, 1993). En otras palabras, los investigadores de esta corriente consideran la predisposición cultural para la actividad empresarial, o bien contemplan los valores culturales como recursos para los empresarios inmigrantes. En un sentido más amplio, algunos investigadores realzan la importancia de los recursos étnicos y de clase para la definición de las iniciativas empresariales exitosas de los inmigrantes (Light y Gold, 2000).

Un segundo eje explicativo empezó a configurarse a partir del reconocimiento de la relevancia de las oportunidades y los obstáculos que los inmigrantes económicos encuentran en la economía o el mercado de trabajo de la sociedad de acogida (Ward y Jenkins, 1984; Aldrich y Waldinger, 1990; Sassen 1995; Jones et alii, 2000). En este contexto, se observó que la actividad empresarial puede surgir como una reacción de la población inmigrante a la discriminación en el mercado de trabajo y/o a los bloqueos en el acceso a oportunidades de movilidad social ascendente. En otras palabras, algunos investigadores contemplan la iniciativa empresarial como una estrategia de supervivencia de inmigrantes que ocupaban una posición marginal en el mercado de trabajo de la sociedad de acogida.

1 La economía abierta se define por oposición a la economía interna de los immigrantes, y corresponde al mercado de trabajo general de la sociedad de acogida. 
Diversos investigadores han defendido que las dos lecturas presentadas no son excluyentes, de manera que es posible que algunas de las iniciativas empresariales de inmigrantes sean resultado de la combinación de varios de estos factores (Ward y Jenkins, 1984; Waldinger et alii, 1990; Kloosterman y Rath, 2001).

Waldinger, Aldrich y Ward (1990) fueron los primeros científicos sociales en subrayar la importancia de que se hiciera una lectura integrada en la investigación de las estrategias empresariales de los inmigrantes, analizando la interacción entre la comunidad y la estructura de oportunidades de la sociedad de acogida.

Más tarde, Kloosterman y Rath (2001), en un análisis crítico de la investigación realizada sobre empresarios inmigrantes, propusieron un modelo teórico complementario basado en las hipótesis de la incrustación mixta (mixed embeddedness). Los autores enfatizan la relación que los inmigrantes establecen entre, por un lado, su incrustación social y cultural y, por otro, su integración económica e institucional en la sociedad de acogida.

Una idea de consenso surge en todas estas aproximaciones teóricas: los inmigrantes se adaptan a los recursos disponibles en los contextos donde se insertan (o en los que están incrustados), lo que varía de país en país y de ciudad en ciudad.

Partiendo de estas distintas líneas conceptuales, en este artículo se pretende discutir y poner de manifiesto la diversidad y el dinamismo de las estrategias empresariales desarrolladas por los inmigrantes en contextos de recepción, que han sido menos estudiados en la literatura.

Como se discutirá en profundidad, a pesar de que Waldinger et alii (1990) fueron los primeros en asumir una perspectiva más inclusiva, no tuvieron en consideración que, a partir de la interacción entre los recursos comunitarios y las estructuras de oportunidad de la sociedad de acogida, se definen diferentes estrategias, más allá de las estrategias estrictamente étnicas.

Por otro lado, como se pondrá de manifiesto, las características culturales y los recursos comunitarios del inmigrante no se definen necesariamente como oportunidades o ventajas para la iniciativa empresarial. En algunos casos, los inmigrantes tienden a depender más de los recursos personales para el éxito de su actividad económica, en especial cuando sus redes de solidaridad se canalizan para trabajos asalariados o no especializados en el mercado de trabajo de la sociedad de acogida (Oliveira, 2005).

En suma, lo que define la estrategia empresarial del inmigrante no son sus raíces culturales o étnicas, sino más bien los recursos y oportunidades que puede movilizar para concretar sus objetivos económicos (Oliveira, 2004a). En consecuencia, las estrategias empresariales de los inmigrantes no son diferentes porque los individuos tengan referencias culturales distintas, sino, principalmente, por las opciones y oportunidades 
a las que tienen acceso. En otras palabras, inmigrantes de diferentes orígenes pueden definir estrategias empresariales semejantes (Oliveira, 2004a).

Con el propósito de clarificar la interacción de esas diferentes dimensiones explicativas de las estrategias de incorporación económica privilegiadas por los diferentes inmigrantes presento en este artículo un modelo heurístico de las estrategias empresariales. Este modelo se prueba y se discute a partir de datos empíricos recogidos en el área metropolitana de Lisboa a partir de 704 cuestionarios realizados entre tres grupos de empresarios de origen inmigrante distintos: chinos, indios y caboverdianos. ${ }^{2}$

Las poblaciones de origen inmigrante estudiadas permiten verificar la diversidad de estrategias de inserción económica de los inmigrantes y demostrar que su diferente propensión a la iniciativa empresarial no resulta de condicionantes culturales, sino de diferencias en cuanto a recursos personales y/o familiares, oportunidades comunitarias y oportunidades y/o constricciones estructurales de la sociedad de acogida (características del mercado de trabajo y contextos legal e institucional).

\section{Revisión de la literatura sobre el empresariado inmigrante: estado de la cuestión}

Los primeros estudios sobre empresarios inmigrantes en las sociedades de acogida tienden a explicar la motivación para la iniciativa empresarial a partir de herencias culturales específicas. ${ }^{3}$ Siguiendo una lógica weberiana, algunos científicos acreditan que es posible identificar valores y referencias culturales que potencian el espíritu emprendedor. Las explicaciones monocausales aíslan la importancia de la familia y de los recursos étnicos ${ }^{4}$ de la comunidad. El énfasis en los recursos étnicos y las redes de solidaridad adquirió relevancia en las teorías de las minorías intermediarias (Bonacich, 1973) y de los enclaves étnicos (Wilson y Portes, 1980; Portes y Manning, 1986), desarrolladas esencialmente en Estados Unidos. En otras palabras, estas perspectivas más culturalistas tienden a enfatizar la etnicidad como factor explicativo, obviando el papel del contexto socioeconómico en que se desarrollan estos negocios.

Estas lecturas basadas exclusivamente en atributos culturales se vuelven peligrosas, en tanto que son responsables de la creación de estereotipos acerca de determinados

\footnotetext{
2 Investigación desarrollada en el ámbito del premio Estímulo à Investigação del servicio científico de la Fundação Calouste Gulbenkian, concedido a la investigadora en 2000, en el área científica «Multiculturalismo y etnicidad en la sociedad contemporánea». Para mayor detalle acerca de las opciones metodológicas de esta investigación, véase Oliveira (2005).

3 Zapalska y Edwards (2001: 289), en su investigación acerca de los empresarios chinos, defienden que la vocación de estos inmigrantes para el negocio es el resultado de su cultura, basada en la ideología de Confucio.

4 Conceptualizado en Light y Gold (2000).
} 
grupos de inmigrantes (Chan y Cheung, 1985: 145). Ivan Light fue el creador de una corriente reactiva de la teoría culturalista, al subrayar que los recursos étnicos (identificados en los modelos culturalistas) no son sólo oportunidades, sino también obligaciones y deberes para los inmigrantes. El autor y sus seguidores demostraron, además, que no todos los inmigrantes de la comunidad tienen acceso de la misma forma a esos recursos u oportunidades.

Las críticas se fundamentaron también en una perspectiva estructuralista materialista, que defiende que la iniciativa empresarial de los inmigrantes se desencadena como resultado de una serie de constricciones (discriminación racial, desempleo prolongado, etc.). En otras palabras, la actividad empresarial inmigrante se define a partir de situaciones de desventaja (y no tanto a partir de recursos étnicos particulares).

Más tarde, Waldinger, Aldrich y Ward (1990), cuestionando las teorías unidimensionales, desarrollaron un modelo interactivo. Según estos autores, las características y los recursos de los grupos de inmigrantes deben considerarse en su interacción con la estructura de oportunidades. Por esta razón, optan por explicar las actividades empresariales de los inmigrantes en relación con el mercado, contemplando la demanda (lo que el contexto de acogida demanda) y la oferta (lo que los inmigrantes ofrecen).

Así, en la estructura de oportunidades de las sociedades de acogida (la demanda), los autores identifican relaciones entre empresarios, consumidores y concurrentes (coétnicos, nativos o de otros grupos de inmigrantes). A su vez, por el lado de la oferta, los autores consideran los factores de predisposición y los recursos que los inmigrantes movilizan en sus redes de contactos privilegiados.

En el modelo interactivo, los autores afirman que las estrategias empresariales resultan de la combinación de factores culturales o de la predisposición de los inmigrantes y de factores político-económicos de la estructura de oportunidades de las sociedades de acogida. En este contexto, afirman que:

«The strategies adopted by the various ethnic groups in capitalistic societies around the world are remarkably similar,» (Aldrich y Waldinger, 1990:131)

El modelo interactivo ofrece una importante contribución para la discusión en este campo científico, principalmente porque define la primera perspectiva inclusiva de las estrategias empresariales de los inmigrantes, que abre nuevas vías para la discusión teórica y la investigación empírica, aunque presenta algunas limitaciones. Como sostiene Rath (2000: 7), Waldinger y sus colaboradores asumen que los inmigrantes definen naturalmente estrategias empresariales étnicas porque comparten una etnicidad o se identifican con un grupo con características étnicas y tradiciones culturales específcas.

Con todo, si la etnicidad se considerase sólo como factor diferenciador de las actividades económicas de los inmigrantes, ¿cómo se podría explicar la iniciativa empresarial 
de individuos de grupos sin experiencia o tradición empresarial? $?^{5}$ En estos casos, las iniciativas empresariales de los inmigrantes ¿serían el resultado de su no identificación con las características de su grupo?

La investigación empírica muestra que incluso los inmigrantes incrustados en su grupo de origen y que comparten prácticas culturales comunes tienen diferentes formas de integrarse económicamente, que no reproducen necesariamente las opciones de la mayoría de sus coétnicos (Oliveira, 2005). En estos casos, las iniciativas empresariales no se explican por las características del grupo y los recursos étnicos, sino por el capital humano y las características individuales del inmigrante, esto es, por sus recursos personales.

Ahora bien, el por qué los modelos teóricos desarrollados han puesto poco énfasis en el papel de los recursos individuales permanece sin respuesta. En particular, ¿cómo individuos pertenecientes a comunidades inmigrantes sin experiencia empresarial o sin el beneficio del apoyo de los contextos de acogida han logrado definir negocios de éxito?

En realidad, contrariamente a lo que defienden Waldinger y sus colaboradores, las estrategias empresariales desarrolladas por grupos de origen inmigrante en diferentes sociedades de acogida son extraordinariamente diversas, incluso comparando inmigrantes del mismo origen. Diversas evidencias empíricas demuestran que los empresarios inmigrantes no definen exclusivamente estrategias étnicas, y que incluso pueden actuar como un empresario nativo. ${ }^{6}$ Adicionalmente, contactos privilegiados con no coétnicos o personas vinculadas a redes sociales no comunitarias pueden ser también una fuente importante de recursos para la estrategia empresarial.

De este modo, los inmigrantes (incluso los del mismo origen) no sólo pueden definir diferentes estrategias empresariales por todo el mundo, sino que también es posible identificar diversas estrategias empresariales en una misma ciudad (Oliveira, 2005).

Fue exactamente con la intención de superar algunas de las limitaciones del modelo interactivo que Kloosterman y Rath (2001) desarrollaron el modelo de incrustación mixta. Según los autores, el estudio de la emprendeduría inmigrante es bastante más complejo de lo que el análisis económico de la relación entre demanda y oferta muestra. En particular, las oportunidades del lado de la demanda deben ser accesibles a los inmigrantes aspirantes a empresarios, circunstancia que no siempre se da. En este ámbito, es fundamental considerar la influencia de los obstáculos, las reglas y las leyes definidas en las sociedades de acogida.

\footnotetext{
5 Véase en Light y Rosenstein (1995) el ejemplo de los cubanos y coreanos en Estados Unidos, o en Oliveira (2005) el caso de los caboverdianos en Portugal.

6 En Portugal se pueden encontrar algunas semejanzas entre las estrategias empresariales de los nativos portugueses y de los inmigrantes, en particular en relación con el recurso al trabajo familiar y al capital financiero de la familia (compárense los resultados de Guerreiro, 1996, y Oliveira, 2005).
} 
Con todo, a pesar de que los autores reconocen que la incrustación de los inmigrantes en las diferentes esferas (cultural, económica, social y política) es compleja y diversa, no tienen en consideración que los inmigrantes pueden usar todas las esferas de inclusión en la definición de su estrategia empresarial, en particular cuando en determinadas esferas se definen constricciones o no existen oportunidades para sus objetivos de inserción económica en las sociedades de acogida.

Por otro lado, se identifica un obstáculo fundamental que explica la diversidad de estrategias empresariales entre los inmigrantes: no todos los inmigrantes tienen acceso a los mismos recursos y oportunidades para desarrollar una estrategia empresarial (Oliveira, 2004a, 2005). Así, el proyecto de delineación de una estrategia empresarial es un proceso creativo e inconstante, toda vez que depende de los recursos y oportunidades que el inmigrante consigue reunir a lo largo del tiempo y en diferentes contextos. En otras palabras, en la definición de una estrategia empresarial, los inmigrantes no interrelacionan necesariamente todas las esferas de incrustación, sino sólo aquellas que potencian su proyecto.

Es a partir de esa lectura crítica de las principales contribuciones disponibles para comprender las estrategias empresariales de los inmigrantes que se presenta en este artículo un modelo teórico tridimensional: el modelo heurístico de estrategias empresariales inmigrantes.

\section{Modelo heurístico de estrategias empresariales de inmigrantes}

Asumiendo la multiplicidad de dimensiones explicativas de las estrategias empresariales de inmigrantes, inherentes a su propia naturaleza social, hemos desarrollado, discutido y avalado un modelo heurístico (Oliveira, 2004a, 2004b, 2005). El modelo propuesto subraya algunos de los elementos explicativos más relevantes (y sus vínculos) para la definición de estrategias empresariales de los inmigrantes en contextos de acogida. El carácter multidimensional de la emprendeduría obliga a incorporar factores racionales y no racionales, económicos y no económicos, egoístas y altruistas, individuales y colectivos, psicológicos y culturales, privados y estructurales. ${ }^{7}$

Se emplea el término modelo heurístico porque la variedad de estrategias empresariales de los inmigrantes aún está por descubrir en su totalidad. Así, con este modelo se pretende proporcionar un punto de partida que ilustre tipos ideales de estrategias empresariales de los inmigrantes, sin pretensión de exhaustividad o creencia en la inmovilidad de la realidad social.

7 Para más información sobre los modelos que profundizan en la naturaleza social de la emprendeduría, véase también Zafirovski (1999). 
El modelo sucede a otras tentativas de probar que no sólo factores ocasionales o aleatorios explican la emprendeduría inmigrante. En particular, subraya los intercambios de recursos e informaciones acerca de oportunidades que los inmigrantes efectúan en las esferas de inclusión. Destaca también el aprovechamiento que los individuos hacen de su capital humano en la definición de la estrategia empresarial. En otras palabras, y adoptando una perspectiva schumpeteriana, el modelo propuesto pretende diferenciar caminos posibles de innovación protagonizada por empresarios inmigrantes, incluido el proceso de combinación dinámica de recursos y oportunidades, o contorno de bloqueos.

Toda vez que las oportunidades no son claras ni transparentes para todos los individuos y no están disponibles para todos los inmigrantes y/o grupos étnicos de la misma forma, las estrategias empresariales son resultado de la negociación, adaptación, imaginación y reproducción (de esquemas de otros empresarios exitosos). De este modo, los inmigrantes reaccionan a las oportunidades y a las constricciones a que se enfrentan durante el proceso de creación de una estrategia.

Esta opción parte de la asunción de que la estrategia empresarial no es sólo una actividad económica, sino también una iniciativa de carácter social. En este sentido, más allá de permitir la realización de un proceso económico, basado en la combinación de factores productivos, la estrategia empresarial se basa en las relaciones de actores sociales con acciones propias (cooperantes o antagónicas).

Se nota, pues, que los empresarios no son actores pasivos, ni muestran un comportamiento totalmente racional en sus opciones económicas. Como discute Etzioni (1988), el hecho de que el individuo tenga un comportamiento económico racional no significa cortar con todas las relaciones privilegiadas, especialmente con los beneficios que le ofrece el grupo étnico. En realidad, esas relaciones privilegiadas pueden formar parte de ese comportamiento económico racional, puesto en práctica en las estrategias empresariales.

De acuerdo con este enfoque, se postula que las estrategias empresariales resultan de una interacción creativa y activa de tres componentes: oportunidades estructurales de la sociedad de acogida, oportunidades comunitarias y recursos personales del individuo (figura 1). En consecuencia, se identifican tres agencias de movilización de la actividad empresarial: 1) la sociedad de acogida, 2) el grupo (coétnico u otro con que el individuo establece relaciones privilegiadas y 3 ) el individuo.

En la primera dimensión (oportunidades estructurales) se enfatizan las oportunidades empresariales que los inmigrantes movilizan en el mercado de trabajo o en los contextos político e institucional. Se considera que, para desarrollar una actividad empresarial legal exitosa, el inmigrante debe encontrar oportunidades de inversión en el mercado y no topar con obstáculos de carácter legal. En otras palabras, se asume que 
la organización de la sociedad de acogida determina desiguales oportunidades ${ }^{8}$ que pueden afectar de forma distinta a diferentes grupos de inmigrantes o individuos.

Figura 1. Modelo heurístico de estrategias empresariales de inmigrantes en sociedades de acogida ${ }^{9}$

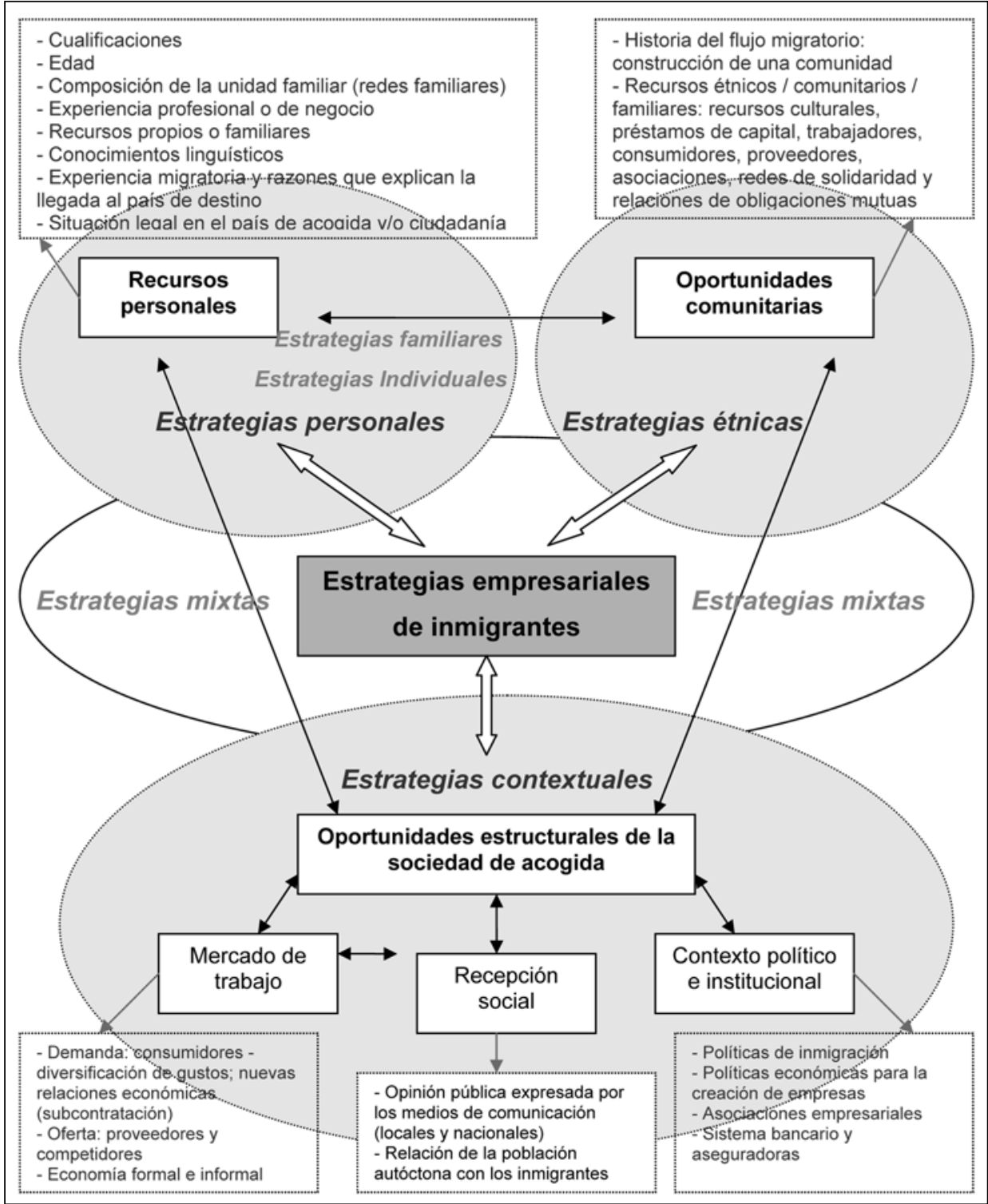

8 Entre esas desigualdades figuran, por ejemplo, el acceso o el control de las fuentes o flujos de información sobre cómo crear una empresa, fuentes de financiación, mercados apetecibles, etc.

9 Adaptado de Oliveira (2004b). 
En la segunda dimensión (oportunidades comunitarias), se considera el papel que desempeñan las redes sociales en las opciones económicas de los individuos. Los estudios sobre las estrategias empresariales de inmigrantes han reafirmado principalmente la importancia de los recursos étnicos ${ }^{10}$ No en vano, las redes sociales pueden proporcionar más como recursos étnicos. Los contactos privilegiados con otros grupos no coétnicos y con la familia pueden resultar asimismo fundamentales en la definición de una estrategia empresarial (Oliveira, 2004b).

Finalmente, y tal vez sea éste un aspecto menos explorado, se considera la intervención de los recursos personales en las estrategias empresariales. Entre estos recursos se incluyen motivaciones o factores de predisposición para la actividad empresarial, apoyos, experiencia de trabajo y empresarial, condición legal en el país de acogida, edad y cualificación. La naturaleza personal de la estrategia empresarial, que incluye las competencias, las aptitudes y el talento del individuo, determina también algunas ventajas competitivas para que el individuo que se mantenga en el juego.

Nótese que la carencia de recursos y oportunidades en una de estas agencias no hace inviable una iniciativa empresarial inmigrante, si existe una fuente bien estructurada que potencie la estrategia. Esta situación es particularmente cierta en el caso de los inmigrantes empresarios exitosos que están incrustados en un grupo sin ninguna experiencia o tradición empresarial en la sociedad de acogida (Oliveira, 2005).

Por otro lado, así como el encuadramiento estructural no se define como agente propiciador o movilizador de la iniciativa empresarial inmigrante, sin embargo, continúa siendo particularmente relevante, toda vez que es condición fundamental de existencia de una organización, de presencia de normas institucionalizadas de funcionamiento en el mercado. Esta organización garantiza a los individuos un conocimiento previo de las reglas de juego y una percepción de las zonas de incertidumbre o dificultad de poner en acción los recursos individuales o comunitarios.

En resumen, las relaciones que se establecen entre estas tres agencias explican por qué algunos inmigrantes tienden a desarrollar actividades empresariales y otros no.

Nótese que las relaciones entre esas agencias se desarrollan siempre a través de los inmigrantes, lo que determina por sí sólo los diferentes flujos de recursos y oportunidades que se establecen para la definición de la estrategia empresarial. Diferentes inmigrantes pueden definir diversos flujos o relaciones entre estas agencias, y por ello definen también estrategias empresariales distintas (Oliveira, 2005). En consecuencia, en la medida en que los proyectos empresariales se definen en la interacción de estas tres agencias, una estrategia refleja siempre la esfera en que el inmigrante consigue reunir más oportunidades y recursos para tener éxito.

10 Véase una sistematización de esas contribuciones en Light y Gold (2000). 
Por otro lado, el encuadramiento en que se define la estrategia empresarial no es estático. Así, modificándose las circunstancias en que se inscribe una estrategia — contexto estructural, comunidad inmigrante o características individuales-, es posible admitir alteraciones en las capacidades y posibilidades que los individuos tienen de movilizar recursos y oportunidades. En resumen, se admite que la caracterización de un universo de estrategias empresariales de los inmigrantes está siempre definida por un tiempo y circunscrita al contexto concreto en que se inserta ${ }^{11}$ Es importante no olvidar nunca que las estrategias no resultan de opciones arbitrarias o fortuitas de los individuos, sino que su funcionamiento resulta de la propia acción del empresario integrado en un espacio de relaciones.

Así, teniendo en cuenta las tres dimensiones explicativas identificadas, se pueden delinear tres situaciones ideales tipo distintas de movilización selectiva de recursos y oportunidades privilegiadas de diferentes esferas de incrustación (Oliveira, 2005):

Estrategias estructurales: estrategias empresariales que nacen de incentivos institucionales $^{12}$ del contexto de acogida o de oportunidades en el mercado que, en tanto que incentivan la actividad empresarial, disminuyen dependiendo de los recursos controlados por instituciones comunitarias. ${ }^{13}$ En estos casos, la incardinación cultural se vuelve menos relevante para las opciones de integración económica de los inmigrantes.

Estrategias étnicas: estrategias desarrolladas por inmigrantes que crean su negocio a partir de los recursos que movilizan en su red social o comunitaria, ignorando las oportunidades estructurales del contexto de acogida. En buena parte de estos casos se da una mera repetición de los esquemas de éxito de otros empresarios coétnicos. ${ }^{14} \mathrm{En}$ otras palabras, a pesar de que los inmigrantes se hallan inmersos en el contexto económico y social del país receptor, pueden mostrar desconocimiento de la demanda o de las necesidades del mercado y limitarse a seguir las opciones de inversión de sus redes de contactos privilegiadas.

Estrategias personales: se trata, tal vez, del tipo ideal menos considerado en la literatura científica de esta área, e ilustra el caso de los inmigrantes que, incluso sin recursos étnicos y sin apoyos en el contexto de acogida, consiguen definir negocios de éxito a partir de sus recursos personales (Oliveira, 2004b). En este contexto, se reconoce que, más allá de los recursos comunitarios y de la posibilidad de confiar en las estructuras de oportunidades de los contextos de acogida, el análisis de las estrategias empresariales de los inmigrantes debe tener en consideración el papel de los recursos individuales

11 A este respecto, véase la discusión en torno al eventual cambio en las estrategias individuales de los empresarios caboverdianos en Portugal (Oliveira, 2005: 155) o considérese la evolución de las empresas industriales portuguesas que, en la década de 1970, se beneficiaban de fuerte apoyo institucional (Cardoso et alii, 1990: 20).

12 Como se observa en el caso de La Haya, en Holanda (Santokhi, 2002).

13 Como también sugieren Sanders y Nee (1996: 233).

14 Las opciones empresariales de muchos chinos en el sector de la restauración por todo el mundo ilustran relativamente bien estas estrategias de «imitación» (Oliveira, 2003). 
o familiares. Admitir la importancia de este capital humano es lo mismo que aceptar que los nativos y los inmigrantes pueden definir estrategias empresariales semejantes.

\section{La diversidad de estrategias empresariales de los inmigrantes: evidencias a partir del caso portugués}

A partir de un estudio realizado en Portugal con empresarios chinos, indios y caboverdianos fue posible observar la gama de estrategias empresariales que desarrollan los inmigrantes. Los datos recogidos en el cuestionario realizado a 704 empresarios en 2002 en el área metropolitana de Lisboa permitirán testar el modelo heurístico discutido y verificar patrones distintos de movilización de recursos y oportunidades inherentes a las tres agencias de actividad empresarial en un contexto de acogida específico.

Antes de avanzar con el análisis propiamente dicho de los resultados del cuestionario, que permiten distinguir las estrategias de los empresarios inmigrantes estudiados, se presenta en este capítulo una breve caracterización de Portugal como contexto de acogida de empresarios inmigrantes. Se pretende también encuadrar las estrategias empresariales inmigrantes en la estructura de acogida en sus diversas dimensiones: económica, social, política y reguladora.

\subsection{La iniciativa empresarial de los empresarios inmigrantes en Portugal}

Durante las últimas décadas el número de empresarios inmigrantes en Portugal ha aumentado significativamente, lo que los ha llevado a dispersarse por todo el país y a desarrollar nuevas estrategias de inserción económica, revitalizando rutas comerciales (algunas abandonadas), creando nuevos productos, definiendo nuevas estrategias de marketing y abriendo nuevos vínculos comerciales entre Portugal y otros países (a veces a través de otros empresarios coétnicos establecidos en otras sociedades).

Siguiendo las tendencias observadas en otros países de acogida, los inmigrantes son más propensos a la iniciativa empresarial que los nativos portugueses (Tabla 1). En efecto, si se considera el peso relativo de los empresarios en la población activa correspondiente, los inmigrantes tienen mayor propensión a ser emprendedores, mientras que los autóctonos tienen mayor peso entre los trabajadores autóctonos (o trabajadores por cuenta propia). ${ }^{15}$

15 Ésta es una de las especificidades del contexto portugués, donde la figura jurídica del emisor de recibos verdes (o trabajador aislado) se confunde, a menudo, con la del empresario. Como concluye Freire (1995: 65), los datos oficiales 
Tabla 1. Población activa portuguesa y extranjera según la situación profesional entre 1981 y 2001

\begin{tabular}{|c|c|c|c|c|c|c|c|c|}
\hline \multirow{3}{*}{$\begin{array}{l}\text { Situación } \\
\text { profesional }\end{array}$} & \multicolumn{6}{|c|}{ Porcentaje por total de población activa } & \multirow{2}{*}{\multicolumn{2}{|c|}{ Tasa de variación }} \\
\hline & \multicolumn{2}{|c|}{1981} & \multicolumn{2}{|c|}{1991} & \multicolumn{2}{|c|}{2001} & & \\
\hline & Portugués & Extranjero & Portugués & Extranjero & Portugués & Extranjero & \begin{tabular}{|l|}
$1981-2001$ \\
Portugueses \\
\end{tabular} & $\begin{array}{l}\text { 1981-2001 } \\
\text { Extranjeros }\end{array}$ \\
\hline Empleador & 3,1 & 5,1 & 6,2 & 7,7 & 9,8 & 10,2 & 259,5 & 1035,9 \\
\hline $\begin{array}{l}\begin{array}{l}\text { Trabajador } \\
\text { autónomo }\end{array} \\
\end{array}$ & 15,2 & 8,9 & 13,1 & 11,4 & 6,1 & 4,5 & $-54,1$ & 187,7 \\
\hline $\begin{array}{l}\text { Trabajador } \\
\text { familiar } \\
\end{array}$ & 2,4 & 1,4 & 1,9 & 1,8 & 0,8 & 0,5 & $-63,6$ & 92,4 \\
\hline Total & 100 & 100 & 100 & 100 & 100 & 100 & 15,5 & 464,7 \\
\hline
\end{tabular}

Fuente: Recenseamentos Gerais da População, Instituto Nacional de Estatística.

Sin embargo, la población inmigrante en Portugal, al igual que ocurre en otros países de acogida, no se puede contemplar como un todo homogéneo. La creciente diversidad de nacionalidades extranjeras en Portugal — cada una con su propia historia, sus redes sociales y sus recursos culturales - hace que haya distintos patrones de inserción en el mercado de trabajo. Así, si algunas poblaciones inmigrantes muestran una notable propensión a la iniciativa empresarial (chinos, ingleses, alemanes y brasileños), otras tienden a insertarse en el mercado de trabajo portugués como trabajadores dependientes (ucranianos, são-tomenses, caboverdianos y guineanos) (Tabla 2). Queda claro, pues, que los inmigrantes no disponen de condiciones homogéneas para la iniciativa empresarial en Portugal.

Si bien es cierto que los factores culturales intervienen y, por tanto, pueden influir en la realidad de los diferentes grupos de inmigrantes en Portugal, en este artículo se pretende poner énfasis en la influencia de los factores contextuales. En este sentido, las oportunidades en la economía portuguesa y las transformaciones estructurales en las políticas y el contexto legal, en períodos específicos de tiempo, tienen una influencia determinante en las opciones de incorporación de los inmigrantes al mercado de trabajo portugués.

La conciencia del potencial de la inmigración es evidente en todo el país; así lo muestran las innumerables iniciativas y proyectos al respecto. Una de esas iniciativas (tal vez una de las más mediáticas de 2006) partió de un alcalde que acogió familias inmigrantes para repoblar, desarrollar y dinamizar económicamente los pueblos del interior del país.

Las instituciones bancarias también se han mostrado particularmente sensibles a las potencialidades de estos nuevos emprendedores. Para el sector bancario, el deseo del inmigrante de emprender se ha visto como una oportunidad comercial o un nicho relativos a ese universo incluyen «falsos independientes» que emiten con regularidad facturas a una única empresa. 
de mercado que explorar. Como resultado, en estos últimos años, diversos bancos han creado líneas de microcrédito para financiar los proyectos de los emprendedores inmigrantes. Algunos de esos servicios resultaron también de los protocolos firmados entre los bancos y la Associação Nacional de Direito ao Crédito (ANDC). ${ }^{16}$

Tabla 2. Tasas de emprendeduría ${ }^{17}$ según la nacionalidad entre 1981 y 2001

\begin{tabular}{|c|c|c|c|c|c|}
\hline Nacionalidad & 1981 & 1991 & 2001 & 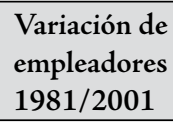 & $\begin{array}{l}\text { Variación } \\
\text { de activos } \\
1981 / 2001 \\
\end{array}$ \\
\hline Total Europa & 12,0 & 13,3 & 9,9 & 2,9 & 3,7 \\
\hline Alemania & 16,1 & 13,8 & 17,7 & 3,7 & 3,3 \\
\hline España & 15,0 & 18,4 & 11,6 & 0,2 & 0,5 \\
\hline Francia & 7,0 & 5,4 & 10,2 & 9,9 & 6,5 \\
\hline Reino Unido & 16,2 & 19,5 & 23,0 & 3,9 & 2,5 \\
\hline Ucrania & & & 1,5 & & \\
\hline Total África & 1,1 & 3,4 & 6,7 & 22,9 & 2,8 \\
\hline Angola & 1,2 & 3,4 & 6,6 & 25,5 & 4,0 \\
\hline Cabo Verde & 0,7 & 3 & 6,4 & 17,3 & 1,1 \\
\hline Guinea-Bissau & 1,9 & 2,9 & 6,2 & 107,2 & 32,1 \\
\hline Mozambique & 3 & 5,9 & 9,1 & 8,0 & 2,0 \\
\hline S. Tomé y Príncipe & 0,2 & 2,6 & 6 & 304,0 & 9,4 \\
\hline Total América & 5,1 & 8,8 & 13,6 & 13,9 & 4,6 \\
\hline Brasil & 4,8 & 9,5 & 13,5 & 20,7 & 6,7 \\
\hline Estados Unidos & 8,5 & 8,3 & 12,3 & 1,7 & 0,9 \\
\hline Venezuela & 3,9 & 7,7 & 13,8 & 11,3 & 2,5 \\
\hline Total Asia & 9,8 & 21,3 & 19,1 & 10,6 & 5,0 \\
\hline China & 22,2 & 24,1 & 36,0 & 31,4 & 19,0 \\
\hline India & 7,9 & 17,6 & 7,6 & 11,3 & 11,7 \\
\hline Pakistán & 17 & 30,7 & 6,3 & 0,9 & 4,2 \\
\hline Oceanía & 1,8 & 9,4 & 14,2 & 20,0 & 1,6 \\
\hline Total & 3,2 & 6,2 & 9,8 & 2,7 & 0,2 \\
\hline
\end{tabular}

Fuente: Recenseamentos Gerais da População, Instituto Nacional de Estatística.

Por otro lado, algunas organizaciones no gubernamentales han desarrollado proyectos con el propósito de estimular la iniciativa empresarial inmigrante. Un ejemplo ilustrativo es el Programa de Desarrollo Comunitario Urbano K'Cidade, que, a través de la creación de Centros de Innovación Comunitaria, pretende promover el desarrollo

16 Asociación que trabaja, desde 1999, para combatir la pobreza y la exclusión social, de acuerdo con la filosofía de crear empleo mediante el apoyo a la creación de microempresas.

17 La tasa de emprendeduría corresponde al número de empleadores por cada 100 activos. 
de las poblaciones más vulnerables. Entre las actividades en curso debe destacarse la formación para pequeños empresarios locales.

También el Estado portugués ha demostrado un particular interés por estimular la iniciativa empresarial de los inmigrantes. El 18 de diciembre de 2006, coincidiendo con el Día Mundial del Inmigrante, el Alto Comisariado para la Migración y las Minorías Étnicas (ACIME) presentó el Anteproyecto del Plano para a Integração dos Imigrantes (PII). Este plan de acción, que será implementado entre 2007 y 2009, involucra a trece ministerios distintos y clarificó, a partir de 122 medidas distintas, la política de acogida e integración de los inmigrantes de Portugal. En su versión final, publicada en la Resolução do Conselho de Ministros n+* 63-A/2007 del 3 de mayo, el plan de acción contempla una medida de incentivo a la emprendeduría de los inmigrantes.

También según la nueva ley de inmigración, el visado de residencia (para la obtención de la autorización de residencia) pasa a poder ser concedido para el desarrollo de una actividad empresarial (según el artículo 60 de la Ley n ${ }^{\circ}{ }^{\circ}$ 23/2007 y el artículo 31 del Decreto Reglamentar n+* 84/2007). La petición de visado se evalúa considerando la relevancia económica, social, científica, tecnológica o cultural de la inversión.

Sin pretensión de representatividad, estos ejemplos ilustran una nueva mentalidad que está naciendo en Portugal, y que contrasta claramente con las lecturas más pesimistas en vigor en décadas anteriores. Así, los inmigrantes empiezan a ser vistos hoy no como una amenaza, sino como una oportunidad; como actores que pueden contribuir al dinamismo de las economías locales y al desarrollo regional.

Con todo, no siempre fue así. En algunos momentos, el contexto legal portugués restringió las iniciativas empresariales inmigrantes. ${ }^{18}$ Dos leyes, en concreto, definirán claros condicionantes:

1. Antes de 1998, la reglamentación de trabajo de los extranjeros en territorio portugués (Decreto Ley 97/77, de 17 de marzo) preveía que «las entidades patronales, nacionales o extranjeras, que ejerzan su actividad en cualquier parte del territorio portugués sólo pueden tener a su servicio, excepto que no sea remunerado, individuos de nacionalidad extranjera, en caso de que su plantilla, cuando ésta esté compuesta por más de cinco trabajadores, esté formada por lo menos por un $90 \%$ de trabajadores portugueses» (artículo 2). Ésta era, pues, una restricción para todos aquellos que pretendían desarrollar estrategias empresariales basadas en la contratación de trabajadores coétnicos (según la literatura, muy frecuente en las estrategias empresariales étnicas). El crecimiento acentuado de los empresarios chinos entre 1991 y 2001 puede reflejar exacta-

18 Para profundizar en estos aspectos, véase Oliveira (2004b). 
mente las consecuencias de la desaparición de los condicionantes de la Ley de Trabajo anterior para este grupo.

2. La ley de regulación de los flujos migratorios, que está en vigor desde julio de 2007, también imponía algunas restricciones. Según el Decreto Reglamen$\operatorname{tar} 6 / 2004$, las dos únicas situaciones legales que hacen viables las iniciativas empresariales de inmigrantes en Portugal eran la autorización de residencia o el visado de trabajo de tipo III. ${ }^{19}$ Teniendo en cuenta que los flujos migratorios del final de siglo estuvieron dominados por individuos titulares de una autorización de permanencia - condición legal que sólo permite al extranjero desarrollar una actividad subordinada (en los sectores donde hay oportunidades de trabajo) - , cerca de 183.833 individuos ${ }^{20}$ no podían, en principio, desarrollar una actividad empresarial en Portugal. En este ámbito, en el marco de la Ley anterior, existía una contradicción: los extranjeros con autorizaciones de permanencia no podían crear su propio empleo, pero podían, en caso de desempleo, inscribirse en el Centro de Empleo y de Formación Profesional y beneficiarse de un subsidio. ${ }^{21}$

Es evidente que la legislación que regula la presencia extranjera en el país determina también las posibles formas de inserción en el mercado de trabajo. En efecto, la condición legal del individuo limita sus estrategias de integración en la sociedad de acogida.

Según el contexto y el año de llegada a Portugal, los inmigrantes encontrarán reglamentaciones distintas y, por tanto, tendrán diferentes posibilidades de movilizar oportunidades y recursos para el desarrollo empresarial en el país. En el caso específico de los tres grupos estudiados, no se puede dejar de tener en cuenta que, mientras los caboverdianos llegaron a Portugal a partir de 1960 —durante la etapa dictatorial y colonial-, los flujos de inmigrantes asiáticos crecieron principalmente a partir de mediados de la década de 1980 — período de transición en que Portugal pasó de ser un país predominantemente emisor a ser también un país de acogida de inmigrantes-. Es también a mediados de la década de 1980 cuando Portugal ingresa en la Comunidad Económica Europea.

19 Es importante tener en cuenta que «o exercício de uma actividade profissional independente por estrangeiro não habilitado com o adequado visto de trabalho ou autorização de residência, quando exigível, fica sujeito à aplicação de uma coima de $€ 300$ a $€ 1200$ » (artículo 144 del Decreto-Ley 34/2003, de 25 de febrero).

20 Según datos del Servicio de Extranjeros y Fronteras, ése es el número de extranjeros con autorización de permanencia concedida entre 2001 y 2004.

21 La nueva Ley de Inmigración buscó combatir algunos de estos bloqueos y dificultades. El primer gran cambio es que, según la Ley n. ${ }^{\circ}$ 23/2007, de 4 de julio, los titulares de diferentes estatutos legales (visado de trabajo, autorización de permanencia, visado de estancia temporal y prórroga de permanencia con autorización para el ejercicio de una actividad profesional subordinada, $y$ visado de estudio) pasan a ser titulares de una autorización de residencia temporal. En este ámbito dejan de definirse diferentes derechos o posibilidades de inserción económica en Portugal en función del estatuto jurídico. Según el artículo 83 de la Ley 23/2007, todo titular de una autorización de residencia tiene derecho, sin necesidad de una autorización especial, al ejercicio de una actividad profesional independiente en Portugal. 
Tabla 3. Año de llegada a Portugal según el origen del empresario

\begin{tabular}{|c|c|c|c|c|c|}
\hline \multirow{2}{*}{\multicolumn{2}{|c|}{ Año de llegada a Portugal }} & \multicolumn{3}{|c|}{ Origen de los empresarios } & \multirow{3}{*}{$\begin{array}{c}\text { Tota } \\
11 \\
\end{array}$} \\
\hline & & \multirow{2}{*}{$\begin{array}{c}\text { Caboverdianos } \\
5 \\
\end{array}$} & \multirow{2}{*}{$\frac{\text { Chinos }}{3}$} & \multirow{2}{*}{$\frac{\text { Indios }}{3}$} & \\
\hline & $\mathrm{N}$ & & & & \\
\hline Década de 1960 & $\%$ & 3,7 & 1,0 & 1,2 & 1,6 \\
\hline \multirow[b]{2}{*}{ Década de 1970} & $\mathrm{~N}$ & 64 & 9 & 91 & 164 \\
\hline & $\%$ & 47,4 & 3,0 & 36,0 & 23,7 \\
\hline \multirow[b]{2}{*}{ Década de 1980} & $\mathrm{~N}$ & 37 & 76 & 114 & 227 \\
\hline & $\%$ & 27,4 & 25,1 & 45,1 & 32,8 \\
\hline \multirow[b]{2}{*}{ Desde 1990} & $\mathrm{~N}$ & 27 & 215 & 20 & 263 \\
\hline & $\%$ & 20 & 71,0 & 7,9 & 38,0 \\
\hline \multirow{2}{*}{$\begin{array}{ll}\text { Nacidos } & \text { en } \\
\text { Portugal } & \\
\end{array}$} & $\mathrm{N}$ & 2 & 0 & 25 & 27 \\
\hline & $\%$ & 1,5 & 0,0 & 9,9 & 3,9 \\
\hline \multicolumn{2}{|l|}{ Total } & 135 & 303 & 253 & 692 \\
\hline
\end{tabular}

Nota: 13 valores omitidos ( 7 no respuestas de caboverdianos y 6 de chinos).

Fuente: Oliveira (2005: 77).

Los empresarios investigados reflejan también la historia de los flujos migratorios de las tres poblaciones (véase tabla 3). Casi la mitad de los empresarios caboverdianos llegó a Portugal durante la década de 1970, y cerca de un $80 \%$ de los empresarios de origen indio, a mediados de la década de 1980; finalmente, un 70\% de los chinos lo hizo en los años noventa - período en que tuvieron lugar dos regularizaciones extraordinarias en el país (en 1992-1993 y 1996) - . La mayoría de los empresarios chinos $(41,7 \%)$ llegó con un visado de turismo, en tanto que una parte importante de los empresarios caboverdianos e indios ya tenía la nacionalidad portuguesa $(28,2 \%$ y $55,3 \%$, respectivamente), reflejo de las pasadas relaciones coloniales con Portugal, y contaban, por tanto, con una condición más estable para el desarrollo de su estrategia empresarial.

El año de llegada puede determinar también la posibilidad de encontrar distintas oportunidades de inserción en el mercado de trabajo. Durante las décadas de 1960 y 1970, se constató el reclutamiento de inmigrantes para responder a las necesidades esencialmente del sector de la construcción civil y las obras públicas. Los inmigrantes oriundos del PALOP vinieron a responder a esas necesidades de mano de obra. Ya a partir de los años ochenta se observa una extensión de las áreas de reclutamiento de los inmigrantes, de manera que aumenta la diversidad de situaciones en la composición socioprofesional de las poblaciones de origen extranjero. Es a partir de esta década cuando comienzan a tener también alguna presencia los profesionales altamente cualificados y los empresarios. 
Según algunos investigadores, a lo largo de las últimas décadas se perfila una etnicización del mercado de trabajo portugués, en tanto que es posible asociar ciertos orígenes de inmigración a determinados sectores económicos (Baganha et alii, 2000). Estas divisiones en la inserción económica de los diferentes orígenes de la inmigración determinan experiencias distintas en el mercado de trabajo y afectan también a la capacidad de movilización de los recursos para definir una estrategia empresarial. La dependencia del grupo coétnico para la inserción económica puede cristalizar en algunas de las opciones de inserción económica y llevar a los inmigrantes a determinados sectores del mercado de trabajo.

Los sectores de inversión empresarial de los investigados acaban coincidiendo bastante con la experiencia profesional de esos inmigrantes en el mercado de trabajo portugués. Así, los empresarios caboverdianos se dedican esencialmente al sector de la construcción (45,1\%); los chinos, al sector de la restauración $(68,3 \%)$ y el comercio al detalle (30,1\%), y los indios, claramente al comercio (86,6\%). Actualmente, esos mismos entrevistados declaran que tenían trabajo antes de desarrollar una actividad empresarial en el sector de la construcción (51,4\% de los caboverdianos), en la restauración (64,7\% de los chinos) y en el comercio (50,6\% de los indios). Atendiendo a este resultado, es importante considerar que, en algunos casos, la experiencia profesional no sólo es un recurso personal, sino que refleja las oportunidades que se ofrecen en el seno de la población coétnica.

Por otro lado, según se ha comentado anteriormente, la percepción de restricciones o de situaciones de desventaja en la sociedad de acogida también puede determinar las acciones de los empresarios de origen inmigrante. Entre las principales dificultades percibidas para el desarrollo de una actividad empresarial en Portugal, la mayoría de los entrevistados subrayan su desconocimiento de las leyes portuguesas (64,9\%). Los empresarios de origen indio y caboverdiano se quejan también de la burocracia de las instituciones y autoridades oficiales portuguesas (43,1\% y 42,6\%, respectivamente). Finalmente, no tener acceso a personas que ocupan lugares clave en las instituciones portuguesas es percibido así mismo por un $18,2 \%$ de los empresarios caboverdianos como una dificultad relevante. ${ }^{22}$

La experiencia de discriminación en el acceso al mercado de trabajo puede convertirse también en una motivación relevante para la creación del propio empleo. En el cuestionario desarrollado se identificaron diferentes experiencias de discriminación en el mercado de trabajo en función del origen del empresario. Los caboverdianos son los que declaran haber tenido mayor experiencia de discriminación en el mercado de trabajo portugués (36,6\%, frente a apenas el 2,9\% de los chinos y el 5,1\% de los indios).

22 Para mayor detalle, véase Oliveira (2005: 82). 
Tabla 4. Experiencias de discriminación por origen del empresario

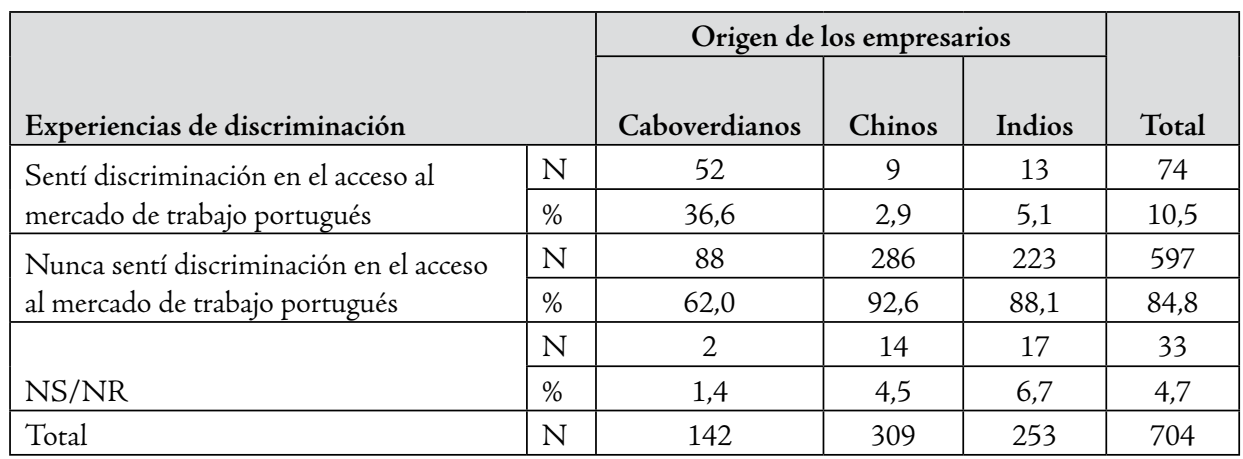

Fuente: Oliveira (2005: 112).

La lectura de estos datos debe tener en consideración, no obstante, las oportunidades o la demanda que se define en el mercado de trabajo y las opciones de inserción económica de los diferentes inmigrantes. Debe distinguir, pues, a los inmigrantes que no compiten directamente en el mercado de trabajo portugués, sino que se insertan en las empresas de empresarios coétnicos. Éstas, precisamente por la naturaleza de su integración económica, circunscrita al grupo coétnico, no identifican o se ven afectadas por el desempleo o la discriminación en el mercado de trabajo portugués.

En resumen, según se ha podido ver, los tres grupos inmigrantes estudiados no tienen acceso al mismo tipo de recursos, experimentan restricciones distintas y no movilizan las mismas oportunidades. Como consecuencia, acaban por definir estrategias empresariales distintas.

\subsection{Tipologías de estrategias empresariales de los inmigrantes: un análisis de correspondencias múltiple}

La técnica de análisis de correspondencias permitió, a través de la lectura de todas las variables recogidas en el cuestionario sociológica y estadísticamente relevantes, visualizar y verificar la clara separación entre combinaciones de recursos y oportunidades distintas. La proyección factorial permite verificar que el nivel de inercia se divide claramente en tres estrategias empresariales distintas: 1) estrategias étnicas, 2) estrategias individuales, y 3) estrategias personales (figura 2). ${ }^{23}$

23 Los dos factores, como proyección de 23 variables, 52 categorías activas y 29 categorías suplementarias, explican el $76,3 \%$ de la variancia $(54,2 \%$ de inercia en el primer factor y $22,1 \%$ en el segundo). 
Las dos últimas estrategias, que surgen de la proyección factorial en oposición a las estrategias étnicas, pertenecen al mismo grupo de estrategias empresariales: estrategias personales. Ambas estrategias resultan predominantemente de la acumulación de recursos de la misma agencia de movilización empresarial. En otras palabras, la interpretación del primer factor (eje 1) interviene en la distinción (y oposición) entre estrategias basadas esencialmente en recursos personales (a la izquierda del eje) y estrategias centradas en oportunidades étnicas (a derecha del mismo eje).

De este modo, la principal dicotomía entre las estrategias empresariales inmigrantes en el área metropolitana de Lisboa en el fin de siglo se define a partir de la importancia relativa de los recursos personales o de las oportunidades comunitarias.

El caso de los empresarios caboverdianos, en particular, permitió poner de manifiesto la existencia de influencias involuntarias inherentes al mercado de trabajo portugués: la identificación de desventajas (por ejemplo, la discriminación en el mercado de trabajo) incentivó la iniciativa empresarial de los inmigrantes.

Este grupo parece ilustrar relativamente bien el tipo ideal de estrategias individuales. Entre las características de este tipo de estrategia se pone énfasis en la asociación positiva con características propias. Cerca del 78,9\% de los empresarios de origen caboverdiano cuenta esencialmente con recursos propios para el desarrollo de su negocio. La escasez de recursos étnicos, en el caso de los empresarios caboverdianos, hace que estos empresarios, inevitablemente, sean más dependientes de la estructura de oportunidades de la sociedad portuguesa y de las condiciones de acceso al crédito bancario.

Por otro lado, los inmigrantes de origen caboverdiano entrevistados esgrimen principalmente razones individuales para el desarrollo de las estrategias empresariales: «quería ser independiente» $(58,8 \%)$, «conocía bien el sector de negocio» $(35,9 \%)$, «quería subir en la vida» $(23,9 \%)$, etc.

Por otra parte, en contraste con los chinos y los indios, los empresarios de origen caboverdiano son los que más manifiestan la intención de regresar al país de origen $(73,9 \%)$ y más invierten en él. El 67,2\% de los empresarios compra propiedades y vivienda, y el 17,9\% invierte en la formación de empresas y nuevos negocios. A diferencia de los otros grupos, además, consideran muy importante que las generaciones más jóvenes continúen sus estrategias empresariales, lo que refleja el gran esfuerzo asociado a la conquista de la posición actual y que contrasta con la mayoría de la población de su país de origen, que se inserta en el mercado de trabajo portugués.

Los empresarios de origen indio parecen retratar relativamente bien el tipo ideal de estrategias familiares. En concreto, se verifica que su estructura empresarial se basa en el recurso al trabajo familiar (apenas el 22,8\% de los empresarios indios declaró no tener trabajadores familiares). Por otro lado, cerca del 54,2\% de esos empresarios afirma tener socios familiares y un 74,3\% dice contar con familiares en el mismo tipo de nego- 


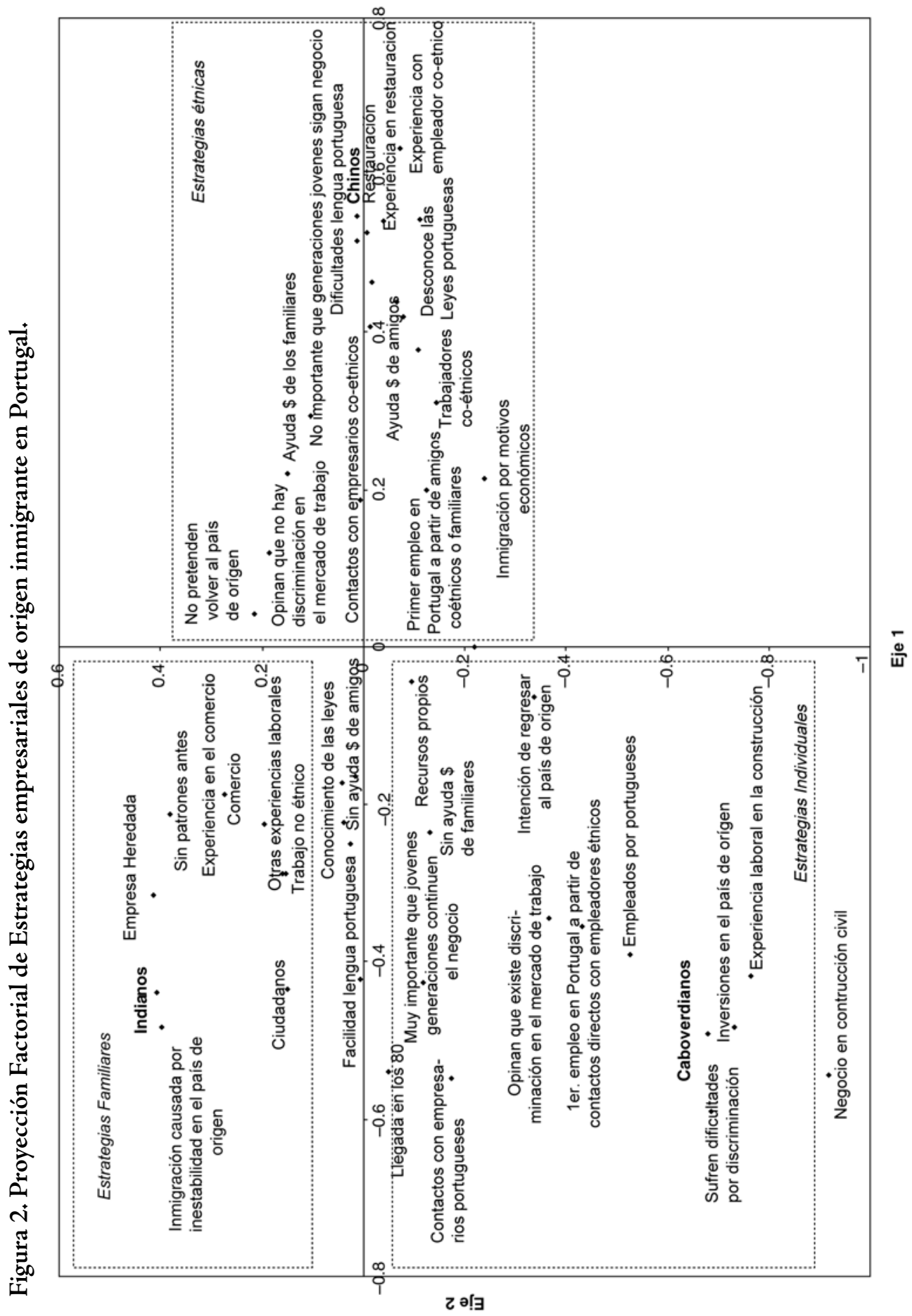


cio. Entre las razones que dieron origen a la actividad empresarial desarrollada en Portugal figuran las «demandas familiares» (25,2\% de los indios cuestionados). Por otro lado, esos empresarios aparecen asociados a actividades en el sector del comercio, pese a que su experiencia profesional no se ciña a ese sector, lo que muestra que la estrategia empresarial, en algunos casos, se basa no tanto en la experiencia del individuo como en la de su familia. Finalmente, cerca del 54,9\% de los empresarios indios desarrolla una actividad por cuenta propia o ayuda en el negocio familiar desde que llegó a Portugal.

Por su parte, los empresarios chinos en Portugal constituyen una clara muestra de las estrategias étnicas. En efecto, en ese grupo se identifican innumerables características del tipo ideal de esas estrategias: el 21,4\% de los empresarios chinos tienen socios coétnicos (frente al 77\% que no tiene socios); el 72,2\% de sus competidores son coétnicos; y basan su estrategia en el apoyo económico de familiares $(66,3 \%)$ y amigos (44\%). Adicionalmente, se debe notar que la mano de obra coétnica es fundamental en el desarrollo de las estrategias empresariales de los chinos: el 52,4\% de esos empresarios da preferencia a la contratación de trabajadores coétnicos y el $98 \%$ dice no tener empleados de otros orígenes. Así las cosas, es evidente que estos empresarios reclutan empleados con quienes establecen relaciones de solidaridad y de confianza, lo que genera un ciclo de reciprocidad. ${ }^{24}$

La red social de la comunidad de origen se mostró también fundamental como fuente de consejos, información y conocimientos estratégicos para los empresarios chinos. Más de la mitad de estos empresarios (50,8\%) dijeron haber llegado a Portugal reclutados por un empleador coétnico. Los contactos con el grupo coétnico facilitaron, además, la obtención del primer empleo en Portugal: el 69,9\% obtuvo el primer empleo en el país con ayuda de amigos, familiares o conocidos coétnicos. Por otro lado, el $71,8 \%$ de esos empresarios declaró tener contactos con coétnicos en la misma área de negocio para el inicio de su actividad empresarial en Portugal. La forma como los empresarios chinos conocen a sus proveedores ilustra también los importantes recursos con que cuenta la comunidad para el desarrollo de la actividad empresarial: el 70,6\% conoció a sus proveedores a través de familiares, amigos o conocidos.

\section{Conclusiones}

Este artículo ha querido poner de manifiesto la diversidad de estrategias empresariales de los inmigrantes y los límites de las generalizaciones respecto a sus tácticas de inserción económica. La literatura en este ámbito había olvidado la existencia de estrategias empresariales más allá de las estrategias étnicas y no había prestado la debida atención

24 Conforme se observó en otros contextos de acogida (Portes, 1999, y Light y Gold, 2000). 
al papel de los recursos personales y familiares de los inmigrantes como agentes movilizadores de la actividad empresarial.

La investigación comparada desarrollada en Portugal a partir de la observación de empresarios de origen caboverdiano, indio y chino permitió contribuir a la discusión de nuevas concepciones teóricas y a la validación del modelo heurístico propuesto. Tomando como referencia las opciones teóricas adoptadas, fue posible identificar tres estrategias empresariales distintas: estrategias étnicas, estrategias individuales y estrategias familiares. En cada una de esas estrategias los empresarios movilizan preferentemente determinados recursos. Estas opciones también se deben a algunas especificidades de la estructura de oportunidades portuguesa. En concreto, determinadas oportunidades estructurales generan mayor o menor dependencia de los recursos de la comunidad coétnica, lo que puede suponer una ventaja para unos (los chinos) y un obstáculo para otros (los caboverdianos).

Las diferencias identificadas para cada una de las tres poblaciones sugieren que no todas las esferas en que se incrustan los inmigrantes se utilizan o movilizan en la definición de la estrategia empresarial. Ni los inmigrantes identifican las mismas oportunidades y constricciones en las esferas en que están inmersos, ni presentan los mismos factores de predisposición a convertirse en empresarios. De este modo, es esencial entender que la definición de una estrategia empresarial es un proceso creativo que resulta de la capacidad del individuo para negociar y reunir recursos en un determinado espacio y momento.

Es, por tanto, fundamental tener en cuenta el factor tiempo a la hora de evaluar estos resultados, toda vez que, como se puso de manifiesto, se observa un cambio progresivo en las estructuras de oportunidades de Portugal en esta vertiente, tanto por iniciativa del Estado portugués (a través del Plano para a Integração dos Imigrantes y los cambios en la Ley de Inmigración) como por iniciativa de organizaciones no gubernamentales (con diversos programas de estímulo al pequeño negocio como forma de combatir la pobreza) y del sector privado (principalmente los bancos).

Finalmente, cabe apuntar una implicación importante que surge de este estudio: es necesario estimular la discusión acerca de los diversos factores que explican la emprendeduría inmigrante desde una aproximación multivariante.

\section{Bibliografía}

Aldrich, H.; Waldinger, R. (1990). «Ethnicity and Entrepreneurship», Annual Review of Sociology, 16:111-135. 
Baganha, M. I.; Marques, J. C.; Fonseca, G. (2000). Is an Ethclass emerging in Europe? The Portuguese case. Lisboa: Luso-American Foundation.

Bonacich, E. (1973). «A Theory of Middleman Minorities», American Sociological Review, 38 (octubre): 583-594.

Chan, J.; Cheung, Y. (1985). «Ethnic Resources and Business Enterprise: A study of Chinese business in Toronto», Human Organization, 44 (2): 142-154.

Etzioni, A. (1988). The moral dimension. Toward a New Economics. New York y Londres: The Free Press.

Guerreiro, M. D. (1996). Familias na Actividade Empresarial: PME em Portugal. Oeiras: Celta.

Jones, T.; Barrett, G.; McEvoy, D. (2000). «Market Potential as a Decisive Influence on the Performance of Ethnic Minority Business», en RATH, J. (ed.). Immigrant businesses. The economic, political and social environment, Londres: Macmillan Press, Ltd, pp. 37-53.

Kloosterman, R.; Rath, J. (2001). «Immigrant entrepreneurs in advanced economies: mixed embeddedness further explored», Journal of Ethnic and Migration Studies, 27 (2): 189-201.

Kloosterman, R.; Rath,J.(2003). «Introduction»,en Kloosterman, R.; Rath, J. (eds.). Immigrant Entrepreneurship. Venturing Abroad in the Age of Globalization, pp. 1-12.

Light, I.; Gold, S. (2000). Ethnic economies. San Diego and London: Academic Press.

Light, I.; Rosenstein, C. (1995). Race ethnicity and entrepreneurship in Urban America. Nueva York: Aldine de Gruyter.

Oliveira, C. R. (2002). "Chinese in Portugal: an immigration cartography», en Fonseca et alii Immigration and Place in Mediterranean Metropolises, Metropolis Portugal, Lisboa: Fundação Luso-America para o Desenvolvimento, pp. 229-254.

Oliveira, C. R. (2004a). «Estratégias Empresariais de origem imigrante em Portugal. Oportunidades étnicas e estruturais e Recursos pessoais», Sociologia Problemas E Práticas, 45: 71-98.

Oliveira, C. R. (2004b). Estratégias empresariais de imigrantes em Portugal. Lisboa: Observatório da Imigração, ACIME.

Oliveira, C. R. (2005). Empresários de Origem Imigrante. Estratégias de Inserção Económica em Portugal. Lisboa: ACIME.

Oliveira, C. R. (2007). «Understanting the diversity of immigrant entrepreneurial strategies», en DANA, L.-P. (ed.). Handbook of Research on Ethnic Minority Entrepreneurship. Cheltenham/Northampton: Edward Elgar, pp.61-82. 
Portes, A. (1999). Migrações Internacionais. Origens, Tipos e Modos de Incorporação. Oeiras: Celta Editora.

Portes, A.; Manning, R. (1986). «The Immigrant Enclave: Theory and Empirical examples», en Olzak, S.; Ángel, J. (eds.). Competitive Etbnic relations, Londres: Academic Press Inc., pp. 47-68.

Portes, A.; Stepick, A. (1993). City on the Edge. The transformation of Miami, Berkeley, Los Angeles y Londres: University of California Press.

Rath, J. (2000). "Introduction: Immigrant Businesses and their Economic, Politic-Institutional and Social Environment», en Rath, J. Immigrant Businesses. The economic, political and social environment. Londres: Macmillan Press Ltd, pp. 1-19.

Sassen, S. (1995). «Immigration and Local Markets», en Portes, A. (ed.). The economic sociology of immigration. Nueva York: Russell Sage Foundation, pp. 87-127.

Solé, C.; Parella, S. (2005). Negocios étnicos. Los comercios de los inmigrantes no comunitarios en Cataluña. Barcelona: Fundació CIDOB.

Waldinger, R.; Aldrich, H.; WARd, R. (1990). Ethnic entrepreneurs. Immigrant business in industrial societies. Sage Publications.

Ward, R.; Jenkins (ed.) (1984). Ethnic communities in business. Strategies for economic survival. Londres: Cambridge University Press.

Wilson, K.; Portes, A. (1980). «Immigrant Enclaves: An Analysis of the Labor Market Experiences of Cubans in Miami», American Journal of Sociology, 86 (2): 295319.

Zafirovski, M.(1999). «Probing into the social layers of entrepreneurship: outlines of sociology of enterprise», Entrepreneurship E Regional Development, 11:351-371.

Zalpalska, M.; Edwards, W. (2001). «Chinese Entrepreneurship in a Cultural and Economic Perspective», Journal of Small Business Management, 39 (3): 286-292. 